\title{
Understanding Competing Fatigue Mechanisms in Powder Metallurgy Ti-6Al-4V Alloy: Role of Crack Initiation and Duality of Fatigue Response
}

Fei Cao, Pankaj Kumar, Mark Koopman, Chenluh Lin, Z. Zak Fang, K. S. Ravi Chandran ${ }^{1}$

Department of Metallurgical Engineering, University of Utah, Salt Lake City, UT, USA

\begin{abstract}
Multiple mechanisms of fatigue crack initiations from pores leading to short-term and long-term fatigue life have been observed in a powder metallurgy (PM) Ti-6Al-4V alloy made by the hydrogen sintering and phase transformations (HSPT) process. The pores in the sintered alloy could be classified into two groups; type-I being caused by particle interstices that did not fully close during sintering (sinter-pores) and the type-II originating from larger voids that did not close during powder packing (cave-pores). The fatigue life trends can be classified by the type and the location of pore from which the crack initiated. Interestingly, the two types of pores, and the two different locations (surface vs. interior) from which the cracks initiated lead to four distinct S-N trends in the fatigue data. When the stress amplitude level and the pore size were accounted for through initial stress intensity factors, the fatigue data reduced to dual S-N fatigue curves. The results offer new insights into how pores, especially their type and size, and location control the fatigue behavior of PM Ti-6Al-4V alloy. Large improvements in fatigue life can be obtained if the large cave-pores are eliminated or their volume density reduced to very low levels.
\end{abstract}

Keywords: Fatigue; Ti-6Al-4V; Powder meta而盂狊lurgy; Crack initiation; Porosity

\section{Introduction}

${ }^{1}$ Corresponding author. Tel: +18015816386

E-mail: Ravi.Chandran@utah.edu 
Powder metallurgy (PM) offers many unique advantages for the mass production of nearnet-shape titanium components [1,2]. The major technical barrier for the adoption of titanium PM parts, in fatigue critical applications, is that even a small amount of porosity can severely degrade fatigue life. The effect of residual pores or defects in reducing fatigue life has been extensively studied in the past [3-12]. However, the conclusions of most of these studies are somewhat expected, in that, the pores have been found to reduce the fatigue life. The concentration of cyclic stress at the surface of the pore leads to early fatigue crack initiation; therefore most of the fatigue life is controlled by propagating the crack $[6,9,11]$. Fatigue data of PM titanium alloys also exhibit large scatter, presumably due to random occurrence of pores of varying size in the specimen. Therefore, it is highly probable that a correlation exists between pore size and/or its physical location (surface versus interior) and the fatigue life.

The present work investigates the fatigue mechanisms in a PM Ti-6Al-4V alloy made by hydrogen sintering and phase transformations (HSPT). In this process, the material is sintered in the $\beta$ phase field of the Ti-H system followed by phase transformations to reduce the grain size [13-16]. Although $\alpha$-grain size was reduced in these materials, the residual pores strongly influence the fatigue behavior. The question of how the pore parameters affect the fatigue behavior was investigated in this work. In this PM Ti-6Al-4V alloy, it has been found that there are two different types of pores. The purpose of this work is to understand how the pore type, size and location affect the fatigue behavior in this HSPT Ti-6Al-4V alloy.

In fatigue of titanium alloys, there are additional complicating aspects such as the recently discovered duality in fatigue behavior [17-20] and the two-stage S-N behavior [21-23] where 
surface and interior crack initiations compete to cause fatigue failure. The duality is caused by the competition between surface and interior crack nucleation from primary- $\alpha$ particle clusters $[17,18]$. Generally, surface crack initiations occur at high stresses, and the associated fatigue life is relatively short because of the environmental effect (from ambient atmosphere) on fatigue crack growth. The crack initiations from interior defects generally lead to long life because of crack growth in a quasi-vacuum environment. This competition in fatigue failure between surface-initiated and interior-initiated cracks may also be present in PM titanium alloys, but there has been no such prior study. Such a study would not only be relevant to the emerging field of PM titanium, but also of particular note from a materials science perspective because the cracks initiate from pores of varying size, location and morphology. Further, interior crack initiation, not associated with any defects can also occur in titanium alloys [23]. In such a case, crack initiation shifts from the surface to the interior, creating a "step" in the S-N curve at lower stress levels $[18,22,24]$. The reason for the transition in fatigue mechanism and the formation of the step has not yet been adequately explained. There can be additional microstructural factors that affect the fatigue behavior, as well. For example, grain boundary alpha phase (GB- $\alpha$ ) that forms under certain microstructural conditions can alter the crack initiation mechanism. Thus the S-N curve or fatigue life can be complex in PM titanium alloys due to pores and microstructure variables.

The objective of this study is to investigate the competing fatigue crack initiation mechanisms from pores in PM Ti-6Al-4V fabricated by HSPT, and to establish clear correlations between the size and location of pores and fatigue life. It is shown that the two types of pores (sinter-pores and cave-pores) lead to complex fatigue failures. Each type of pore and its location (surface or interior), has its own S-N curve. It is also shown that based on the initial stress 
intensity factor, the fatigue life trends can be effectively rationalized into two $\mathrm{S}-\mathrm{N}$ curves, confirming that dual fatigue failure response also occurs in the present material.

\section{Material and experimental procedure}

The PM Ti-6Al-4V alloy bars were $15 \mathrm{~mm}$ in diameter and $80 \mathrm{~mm}$ in length, and were fabricated from titanium hydride powder following the HSPT process described elsewhere [13]. Basically, the process involves first cold isostatic pressing (CIP) of $\mathrm{TiH}_{2}$ powder (-325 mesh, average particle size is $17 \mu \mathrm{m}$, acquired from Reading Ametek) blended with 60 wt. \% Al-40 wt. \% $\mathrm{V}$ master alloy powder $(-325 \mathrm{mesh}$, average particle size is $16 \mu \mathrm{m})$. The proportion of master alloy powders was selected according to the chemical composition of Ti-6Al-4V alloy. After CIP, the samples were sintered at $1200^{\circ} \mathrm{C}$ for 4 hours in a flowing atmosphere of $\mathrm{Ar} / \mathrm{H}_{2}(50 / 50)$ gas mixture. The sintered samples were then phase-transformed through eutectoid temperature and held at $650{ }^{\circ} \mathrm{C}$ for 4 hours. This was followed by dehydrogenation at $750{ }^{\circ} \mathrm{C}$ for 12 hours to yield solid Ti-6Al-4V alloy with a homogeneous and fine $\alpha+\beta$ microstructure. The average sintered density achieved after the processing was $99.4 \%$. The chemical composition of the sintered Ti6Al-4V PM alloy was determined to be (in wt. \%): $5.99 \mathrm{Al}, 3.84 \mathrm{~V}, 0.42 \mathrm{O}, 0.008 \mathrm{~N}$, and 0.0005 H.

Three dimensional X-ray microtomographic imaging was performed on the cold isostatic pressed powder compact and the sintered alloy to map the distribution of residual pores. The imaging was done using an Xradia (model: micro XCT-400) high-resolution X-ray microtomographic unit. The tomographic scan was performed with a peak X-ray voltage of 80 $\mathrm{kV}$ with the specimen rotating along its axis. A total of 994 2-D radiographs were obtained. The 
2-D radiographs were reconstructed to obtain 3-D X-ray image with a voxel of $4.59 \mu \mathrm{m} \times 4.59$ $\mu \mathrm{m} \times 4.59 \mu \mathrm{m}$. This enabled 3D visualization of pores of size $5 \mu \mathrm{m}$ and above.

The sintered bars were machined to produce cylindrical fatigue specimens, each having a total length of $76.2 \mathrm{~mm}$. The gauge sections were $6.35 \mathrm{~mm}$ in diameter and $12.7 \mathrm{~mm}$ in length. The test sections were polished using several grades of silicon carbide paper until grade 1200, followed by finishing with $1 \mu \mathrm{m}$ alumina suspension to obtain surfaces free from machining or polishing-induced damage. Tension-tension fatigue tests were conducted under load control with a cyclic frequency of $35 \mathrm{~Hz}$ (sine wave) at a stress ratio $\left(\sigma_{\min } / \sigma_{\max }\right)$ of 0.1 . The fatigue tests were conducted in laboratory air and at room temperature. Fatigue fracture surfaces were examined in an SEM to determine the characteristics of fatigue crack initiation. The areas $\left(A_{p}\right)$ of initiating pores present on the fracture surfaces were determined using ImageJ software. For each pore, the equivalent circular diameter $\left(D_{e}=\sqrt{4 A p / \pi}\right)$ was calculated.

\section{Result and discussion}

\subsection{Microstructures and fatigue failure initiations of PM Ti-6Al-4V}

The microstructure and pore types of the PM Ti-6Al-4V alloy are shown in Fig. 1. Figure 1(a) shows typical small pores with rounded edges (termed, "sinter-pores"), which are the most common in the microstructure. The rounded edges suggest that these pores evolved from prior interstitial spaces between the $\mathrm{TiH}_{2}$ particles, by creep flow of matter along the edges during sintering. Figure 1(b) shows an example of large pores (termed, "cave-pores") that are present in the microstructure in far fewer numbers relative to sinter-pores. They are thought to originate from larger voids formed by particles that had locked-in before sintering to form gaps between poorly packed particles. Figure 2(a) shows the 3D distribution of pores in the cold pressed green 
compact before sintering as determined by x-ray microtomography. Figure 2(b) is an arbitrary slice through the volume of a specimen showing the presence of large $(>100 \mu \mathrm{m})$ cave-pores, possibly due to local locking of titanium hydride particles during CIP. Because the titanium hydride particles are angular and their flowability is poor, formation of caves during particle packing in the green state can be expected. Figure 2(c) shows the presence of a large cave-pore and some small sinter-pores in an arbitrary 2D slice through the 3D microtomographic construction image of the sintered specimen. The full 3D image is shown in Fig. 2(d).

When all the fatigue tests results were reviewed, it was found that fatigue failures occurred due to cracks starting from either of the two pore types. For the crack initiation pores, the equivalent diameters (approximated to circles having the same total pore area measured on the fracture surface) ranged from $20-340 \mu \mathrm{m}$. The distribution of these pore diameters are presented in the form of the largest extreme value distribution (LEVD) plots in Fig. 3. The extreme value distribution plotting is a well-established method of presentation of the defect distribution in a material, and is discussed in detail elsewhere [25]. In this method, the pore diameters are ranked in order from small to large, and the cumulative ranking is determined. The cumulative rank is given by

$P_{j}=-\ln \left(-\ln \left(F_{j}\right)\right)$

where

$\mathrm{F}_{\mathrm{j}}=\mathrm{j} \times 100 /(\mathrm{n}+1)$

Where $\mathrm{j}$ is the rank when arranged in ascending order of pore size, and $\mathrm{n}$ is the total number of observations. The cumulative rank is plotted against the equivalent pore diameter to illustrate the distribution of pore size in the present material, as shown in Fig. 3. The data in the figure supports the discrimination between two types of pores shown in Fig.1. The plot reveals 
that the residual sinter pores (type-I pores with size range: $20 \sim 75 \mu \mathrm{m}$ ) and the cave pores (type-II pores with size range: $78 \sim 340 \mu \mathrm{m}$ ) each exhibit their own unique distribution. The transition between the two distributions occurs at a pore size of about $75 \mu \mathrm{m}$. Both types of pores were found to initiate fatigue cracks from the surface or the interior of the specimen at a range of applied stress levels. Typical crack initiating pores are shown in Fig. 4. Figures 4 (a) and (b) are typical examples of crack initiation from type-I sinter-pores. Figures 4(c) and 4(d) are typical examples of crack initiation from type-II cave-pores.

\subsection{S-N curves of PM Ti-6Al-4V by HSPT}

Figure 5 shows S-N fatigue data, plotted in the form of the maximum cyclic stress $\left(\sigma_{\max }\right)$ versus the number of cycles to failure $\left(\mathrm{N}_{\mathrm{f}}\right)$ of all the samples tested. The data were identified and grouped according to the fatigue failure initiation modes. That is, distinct grouping of data in terms of fatigue crack initiation mechanisms, namely, surface versus interior crack initiation and/or whether the cracks initiated from a type-I or a type-II pore. It is to be noted that all pores that were located at a distance (the distance between specimen edge and the closest point on the pore surface) greater than the pore diameter were taken as interior pores. In fatigue of a defectfree material, a nucleation life is usually involved in the formation of a fatigue crack. In this work however, we find that the pores readily initiated cracks, therefore the fatigue life can be considered to be almost entirely made of crack propagation life $[6,9,11]$. Thus, there is no crystallographic or microstructural related crack initiation mechanism.

The data in Fig. 5 reveals that there are actually four distinct trends in the fatigue data. On the macroscopic level, the S-N curves separate naturally with two major parts: a short- termlife (STL) domain and a long-term-life (LTL) domain, reflecting the duality of the fatigue 
phenomenon $[17,18]$. However, within the STL and LTL domains, the data were found to order into two subgroups, depending on the pore type from which the crack initiated. The fatigue curves A and B in Fig. 5 are made of failures from type-I pores. On curve A, all the specimens failed from type-I pores that were located at the surface. On the other hand, failures from type-I pores that were located in the interior of the specimen formed the failure curve B.

The fatigue curves $\mathrm{C}$ and D in Fig. 5 are largely due to fatigue cracks initiating from type-II pores. Type-II pores that were located at the surface produced the shortest fatigue lives (curve C) and those that were located internally produced relatively longer fatigue lives (curve D). It is interesting to note that the cracking from type-I pores produced relatively longer fatigue lives, compared to those initiated from type-II pores. This is to be expected, because the size range of type-I pores was smaller than that of type-II pores.

It is therefore evident that short-term-life failures can be caused by both types of pores, located at or close to the specimen surfaces. There are two factors that are responsible for the relatively short fatigue lives. One is the geometrical effect, the geometry factor in equation (1) for surface pores is $30 \%$ higher than that for interior pores in equation (2). Secondly, the propagation of a surface crack is affected by the laboratory air environment leading to accelerated crack growth. Oguma et al. [26] have shown that the crack growth rate of Ti-6Al-4V in a room temperature air environment is significantly higher than that in vacuum. Hence, both the increased level of stress concentration and the exposure to the laboratory air environment reduces the fatigue life of these specimens relative to the internal pores.

There are however some exceptions to the classification above. In one fatigue specimen, failure started from an internal type-II pore, as indicated by a solid diamond symbol in Fig. 5. It 
was surprising to observe that an internal pore provided the shortest fatigue life, despite the fact that its crack initiation and growth was not influenced by the outside environment. Upon examination of the fracture surface, it was found that this initiating pore had an equivalent diameter of $274 \mu \mathrm{m}$ and the applied stress in that fatigue test was the largest (700 MPa) of all tests performed, leading to the largest initial stress intensity factor. Though this was an internal pore, it appears that the crack initiation occurred readily because of the higher level of stress. This is thought to be the reason for this particular data point falling in curve C.

Another exception to the four distinct trends discussed above were the failures from large GB- $\alpha$ regions. Four samples marked with black $X$ symbols in Fig. 5 were short-life fatigue failures, but failed from crack initiations from interior regions of the specimens. The fatigue fracture surfaces of these specimens indicated unusual fracture features, typically connected with fracturing of thick GB- $\alpha$. As shown in Fig. 6, when cracks initiated from certain pores (regardless of Type-I or II), they tended to be located adjacent to a GB- $\alpha$ region. These cracks apparently propagated faster. The GB- $\alpha$ region provided a path for rapid propagation along the grain boundary, causing fracture steps and ligaments (indicated by arrows in Fig. 6) that are orientated in the projected direction of the GB- $\alpha$. The combination of GB- $\alpha$ with the crack initiating pores, resulted in relatively shorter fatigue life. This is the primary reason for the internally-initiating cracks producing short-term fatigue lives.

The four trends in S-N data indicate a four-way competition for fatigue failure in the Ti6Al-4V alloy manufactured by the PM route: 
(i) surface-initiated failures with the shortest fatigue lives from type-II pores located at the surface. This also includes the exceptions: large type-II pore located internally (high stress level), as well as pores located in the proximity of GB- $\alpha$ in interior regions;

(ii) surface-initiated failures with relatively shorter (but not the shortest) fatigue lives, exclusively from type-I pores that statistically occurred at the surfaces of samples;

(iii) interior-initiated failures from type-II pores located internally in the specimen, producing relatively longer fatigue lives;

(iv) interior-initiated failures from type-I pores located in the bulk of the specimens, producing the longest fatigue lives.

\subsection{Duality of $S-N$ curve or Fatigue Behavior}

From the point of view of fatigue life, it is important to recognize that the principal difference between type-I and type-II pores is their size range. This can be seen in Fig. 5 where the internally located type-II pores (which are generally much larger than type-I pores) actually produced longer fatigue life than the type-I pores that happened to be located at the surface. It seems that environmental exposure (being located at the surface was more damaging than the size of the pore itself) had a dominant effect, overriding the effect of high stress concentration at a large pore. In order to evaluate this aspect, the crack initiation stress intensity factors were determined using Murakami's equations for stress intensity factors for 3-D cracks. The initial stress intensity factors, assuming that pores behave as cracks, were estimated according to the equations proposed by Murakami et al. [27]:

$$
\Delta \mathrm{Ks}=0.65 \Delta \sigma \sqrt{\pi D_{e}}
$$


for a surface pore and

$$
\Delta K_{I}=0.5 \Delta \sigma \sqrt{\pi D_{e}}
$$

for an internal pore, respectively. Here, $\mathrm{D}_{\mathrm{e}}$ is the equivalent pore diameter.

Figure 7 shows the initial stress intensity factor values $\left(\Delta \mathrm{K}_{\mathrm{S}}, \Delta \mathrm{K}_{\mathrm{I}}\right)$ versus the equivalent pore diameters for all the fatigue specimens tested in this study. The data are grouped into two categories: (i) short term fatigue life and (ii) long term fatigue life. It can be seen that all of the fatigue crack initiations that had a higher crack initiation stress intensity factor had a short term life. The ones with the lower initial stress intensity factor $\left(\Delta \mathrm{K}_{\mathrm{S}}, \Delta \mathrm{K}_{\mathrm{I}}\right)$ had relatively longer fatigue lives. Both types of pores, covering the entire initiation pore-size range of $20 \sim 340 \mu \mathrm{m}$, were involved in both life domains. Thus, it is clear from Fig. 7 that the competition between short-term life and the long-term life is also affected by the initial stress intensity factor levels, in addition to the location (surface versus interior) where they occur.

It is then possible that if the initial stress intensity factor and the location are factored into the analysis, the four distinct curves in Fig. 5 might condense into two distinct curves, one for short-term life and the other for the long-term life. This is affirmed in Fig. 8, where the S-N fatigue curve has been plotted in terms of the initial stress intensity factor for the specimens tested in this study. The two separate curves in Fig. 8 indeed confirm the duality of fatigue response. This figure indicates that when the pore size effects are accounted for, the dual fatigue behavior emerges in the data, one for environmentally affected short-life behavior and the long life behavior which is free from any environmental effect.

Figure 8 reveals an apparent threshold initial stress intensity factor (about $3.2 \mathrm{MPa} \sqrt{\mathrm{m}}$ ) for type-I specimens, which separates the STL and LTL domain clearly. The threshold initial 
stress intensity factor for failures from the type-II pores is not as clear as that of type-I. One reason might be that most of type-II pores have irregular shapes, making the estimated stress intensity factor deviate from the true stress intensity factor.

In Fig. 8 the $\mathrm{X}$ symbols are the specimens in which the crack initiations occurred from internal pores, but were found to be aided by GB- $\alpha$. The crack propagating path (GB- $\alpha$ ) can provide lower resistance to cleavage crack extension because of the absence of ductile beta phase in the path of the crack [28]. Figure 8 also shows one specimen (diamond symbol) where the crack initiated from an internal pore and had the highest initial stress intensity factor. Both of these exceptions indicate that the location of failure initiation site is not the only factor that necessarily affects the fatigue life. This is supported by the observations of Lankford et al. [4]. In Lankford's study, the fatigue life was more closely related to the diameter of inclusions than to whether the nucleating particle was located at the surface or internal. Yokoyama et al. also found that the internal crack initiation site itself has nothing to do with the fatigue life [29], but the stress level and defect size are contributing factors. The influence of defect size may overtake the effect of both the crack propagation environment and the crack initiating location. This is consistent with the present study, because most of the fatigue life was essentially occupied by the crack propagation cycles to rupture. Which pore becomes the main crack initiator in a specimen is always a competitive process and depends on the size and the stress level. The results of this work confirm that the most dominant mechanism will be decided by the site with the greatest initial stress intensity factor, regardless of the location of the pore, or whether supplemented by environment effects or not.

\section{Conclusions}


The fatigue behavior of a powder metallurgy Ti-6Al-4V alloy made from titanium hydride powder by the HSPT process has been studied. The main results are summarized as follows:

1. Multiple crack initiations for small and large pores located either internally or at surfaces were shown to cause four distinct trends in fatigue failures. The four trends in S$\mathrm{N}$ data indicate a four-way competition for fatigue failure in the present material.

2. The surface-initiated failures with the shortest fatigue lives were caused by type-II pores (larger cave-pores) located at surfaces, and large type-II pores located internally or from any pore located in the proximity of GB- $\alpha$ in interior regions. All these failures formed a unique S-N curve.

3. The surface-initiated failures with relatively shorter (not the shortest) fatigue lives, were caused exclusively by type-I pores (smaller sinter-pores) that statistically occurred at surfaces of samples. These specimens formed their own distinct S-N curve.

4. The interior-initiated failures from type-II pores located internally in the specimen, producing relatively longer fatigue lives, formed separate $\mathrm{S}-\mathrm{N}$ curve.

5. The interior-initiated failures from type-I pores located in the bulk of the specimen, produced the longest fatigue lives. These failures formed separate S-N curve.

6. When the crack initiating pore size was accounted for in terms of initial stress intensity factor, a dual S-N fatigue response was resulted, supporting earlier observations in fatigue of structural materials. 


\section{Acknowledgment}

The authors gratefully acknowledge the financial support from the US Department of Energy, Innovative Manufacturing Initiative (DEEE0005761), through the Advanced Manufacturing Office and the Office of Energy Efficiency and Renewable Energy. The powders were supplied by Reading Alloys Inc. Robesonia, PA. We thank Pei Sun and James Paramore for their help in sample preparations, and Yan Wang for the X-ray microtomography scans.

\section{References}

[1] F.H. Froes, C. Suryanarayana, Rev. Part. Mater. 1 (1993) 223-275.

[2] M. Hagiwara, S. Emura, Mater. Sci. Eng. A 352 (2003) 85-92.

[3] J.Z. Yi, P.D. Lee, C. Lindley, T. Fukui, Mater. Sci. Eng. A 432 (2006) 59-68.

[4] J. Lankford, F.N. Kusenberger, Metall. Trans. 4 (1973) 553-559.

[5] Y. Yan, G. Liu, P. Nash, Int. J. Fatigue 55 (2013) 81-91.

[6] X. Zhu, J.Z. Yi, J.W. Jones, J.E. Allison, Metall. Mater. Trans. 38A (2007) 1111-1123.

[7] Y. Murakami, S. Kodama, S. Konuma, Int. J. Fatigue 11(5) (1989) 291-298.

[8] A. De Bussac, Fatigue Fract. Eng. Mater. Struct. 17 (11) (1994) 1319-1325.

[9] Y. Jang, Y.Jeong, C. Yoon, S. Kim, Metall. Mater. Trans. 40A (2009) 1090-1099.

[10] P. Li, P.D. Lee, D.M. Maijer, T.C. Lindley, Acta Mater. 57 (2009) 3539-3548.

[11] J.Z. Yi, Y.X. Gao, P.D. Lee. H.M. Flower, T.C. Lindley, Metall. Mater. Trans. 34A (2003) 1879-1890.

[12] O.M. Ferri, T. Ebel, R. Bormann, Mater. Sci. Eng. A 527 (2010) 1800-1805.

[13] Z.Z. Fang, P. Sun, H. Wang, Advanced Eng. Mater. 14(6) (2012) 383-387. 
[14] P. Sun, Z.Z. Fang, M. Koopman, Advanced Eng. Mater. 15(10) 2013 1007-1013.

[15] P. Sun, Z. Z. Fang, M. Koopman, J. Paramor, K.S. Ravi Chandran, Y. Ren and J. Lu, Acta Mater. 84 (2015) 29-41.

[16] D.H. Kohn, P. Ducheyne, J. Mater. Sci. 26 (1991) 534-544.

[17] K.S. Ravi Chandran, Nature Mater. 4 (2005) 303-308.

[18] K.S. Ravi Chandran, S.K. Jha, Acta Mater. 53 (2005) 1867-1881.

[19] S.K. Jha, K.S. Ravi Chandran, Scripta Mater. 48 (2003) 1207-1212.

[20] K.S. Ravi Chandran, P. Chang, G.T. Cashman, Int. J. Fatigue 32 (2010) 482-491.

[21] D.F. Neal, P.A. Blenkinsop, Acta Metall. 24 (1976) 59-63.

[22] A. Atrens, W. Hoffelner, T.W. Duerig, J.E. Allison, Scripta Metall. 17 (1983) 601-606.

[23] O. Umezaw, K. Nagai, ISIJ Int. 37(12) (1997) 1170-1179.

[24] O.Umezawa, K. Nagai, K. Ishikawa, Mater. Sci. Eng. A 129 (1990) 217-221.

[25] S. Berett, Y. Murakami, Metall. Mater. Trans. 32B (2001) 517-523.

[26] H. Oguma, T. Nakamura, Int. J. Fatigue 50 (2013) 89-93.

[27] Y. Murakami, S. Kodama, S. Konuma, Int. J. Fatigue 11(5) (1989) 291-298.

[28] K. S. Ravichandran, E. S. Dwarakadasa and D. Banerjee, Scripta Metall. Mater. 25 (1991) 2115-2120.

[29] H. Yokoyama, O. Umezawa, K. Nagai, T. Suzuki, ISIJ Int. 37 (1997) 1237-1244. 


\section{Figure Captions:}

Fig. 1. Microstructures of PM Ti-6Al-4V alloy densified by HSPT (a) residual sinter-pores, (b) a large cave-pore, originating from big void that existed before sintering, (c) the overall microstructure including the prior-beta grain boundaries and (d) SEM micrograph of the fine $\alpha+\beta$ microstructure.

Fig. 2. X-ray microtomographic imaging showing the size and distribution of pores (a) 3D reconstructed image of a cold isostatic pressed powder compact, (b) an arbitrary 2D radiograph showing the presence of a cave, (c) a 2D slice of as-sintered Ti-6Al-4V alloy specimen, (d) 3D reconstruction of as-sintered Ti-6Al-4V alloy specimen.

Fig. 3. Largest extreme value distribution plot of fatigue crack initiating pores in the PM Ti-6Al4V alloy.

Fig. 4. Examples of fatigue crack initiations from pores (a) type-I internal pore $\left(\sigma_{\max }=460 \mathrm{MPa}\right.$, $\mathrm{N}_{\mathrm{f}}=1988166$ cycles); (b) type-I surface pore ( $\sigma_{\max }=700 \mathrm{MPa}, \mathrm{N}_{\mathrm{f}}=42076$ cycles $)$; (c) type-II internal pore, $\left(\sigma_{\max }=600 \mathrm{MPa}, \mathrm{N}_{\mathrm{f}}=606535\right.$ cycles $)$; (d) type-II surface pore $\left(\sigma_{\max }=550 \mathrm{MPa}, \mathrm{N}_{\mathrm{f}}\right.$ $=36604$ cycles $)$.

Fig. 5. S-N curve of PM Ti-6Al-4V alloy specimens distinctively grouped on the basis of initiating pore types and their location in the specimen.

Fig. 6. Example of fatigue fracture surfaces of short term life specimens initiating from internal pores when they were associated with GB- $\alpha$ (a) $\sigma_{\max }=500 \mathrm{MPa}, \mathrm{N}_{\mathrm{f}}=36480$ cycles; (b) $\sigma_{\max }=$ $650 \mathrm{MPa}, \mathrm{N}_{\mathrm{f}}=22615$ cycles. 
Fig. 7. Relationship between the initial stress intensity factor and equivalent initiating pore diameter.

Fig. 8. Relationship between initial stress intensity factor and corresponding fatigue life. 


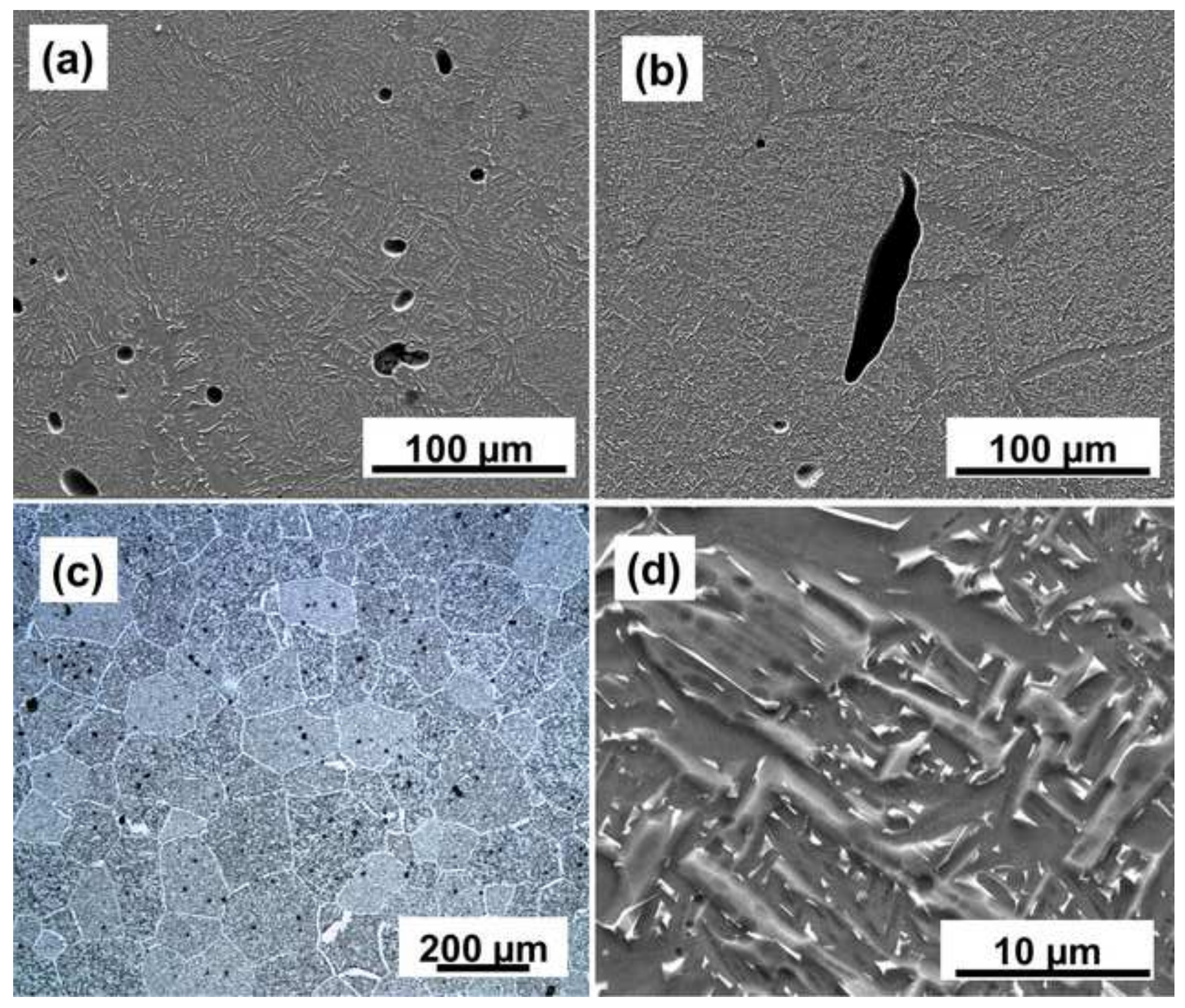


(a)
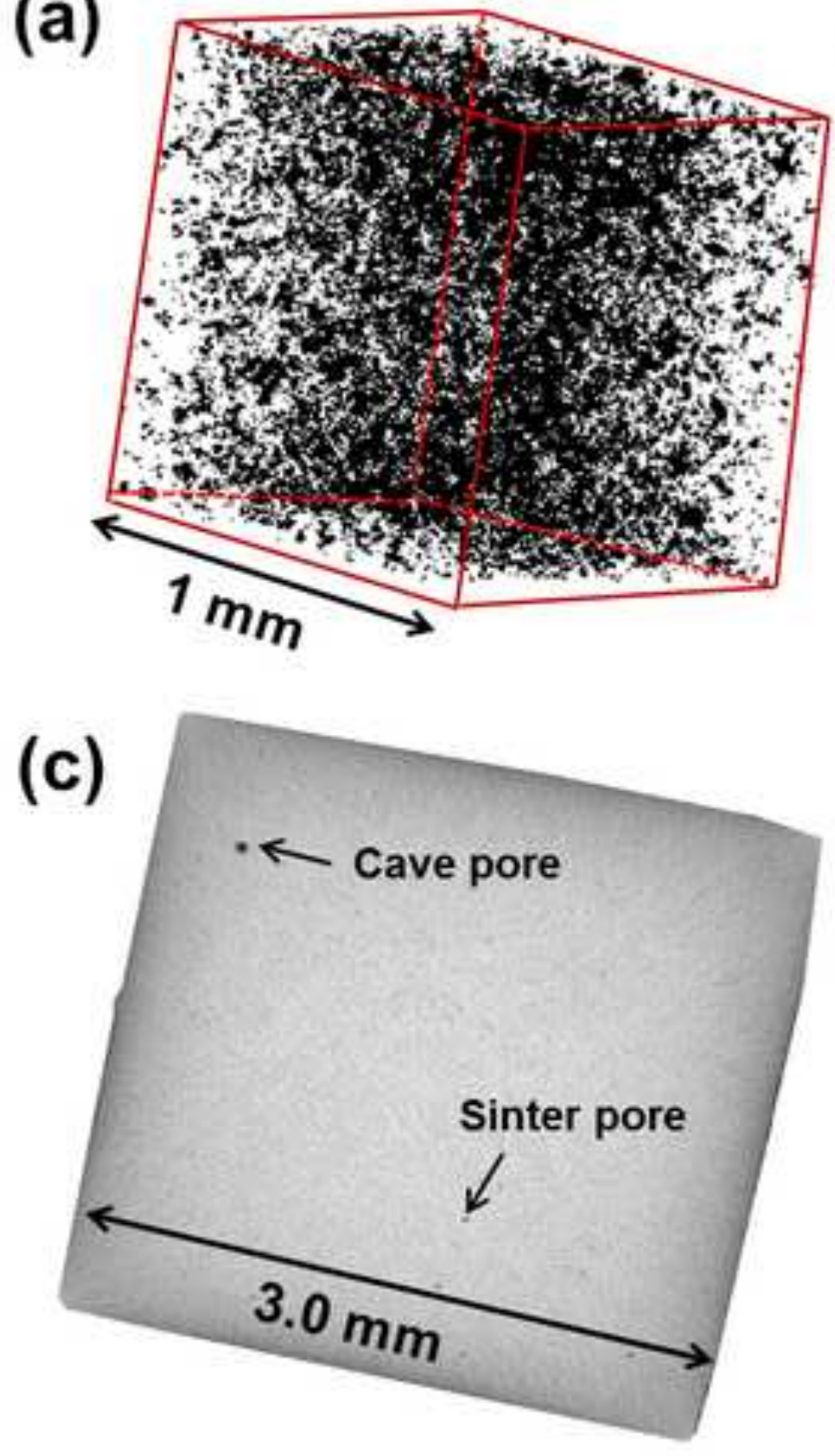

(b)

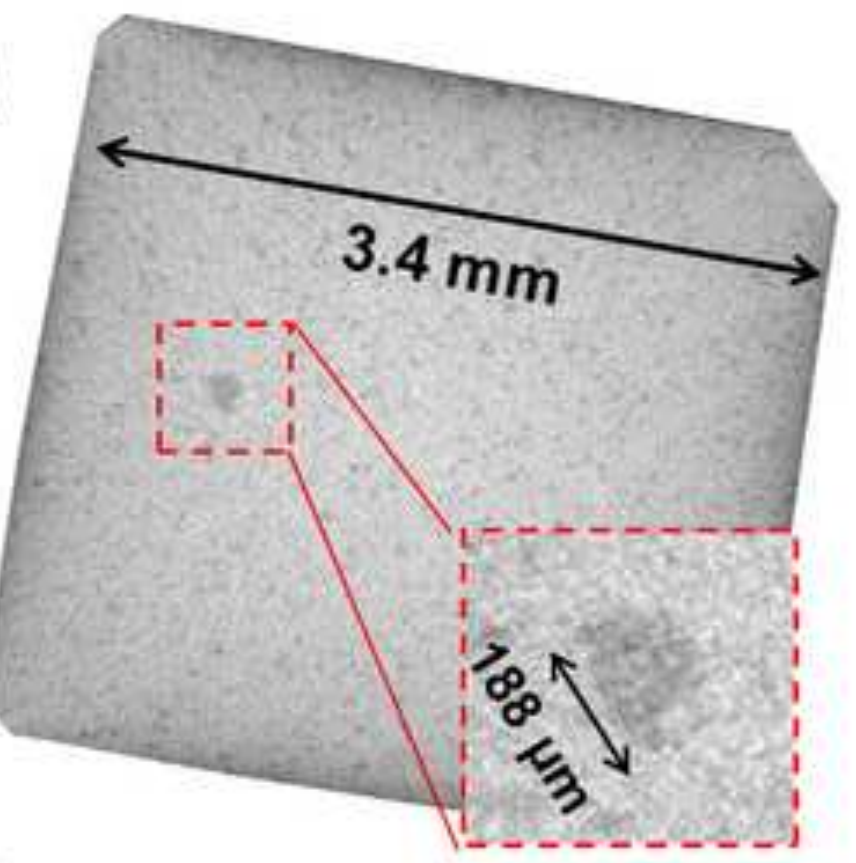

(d)

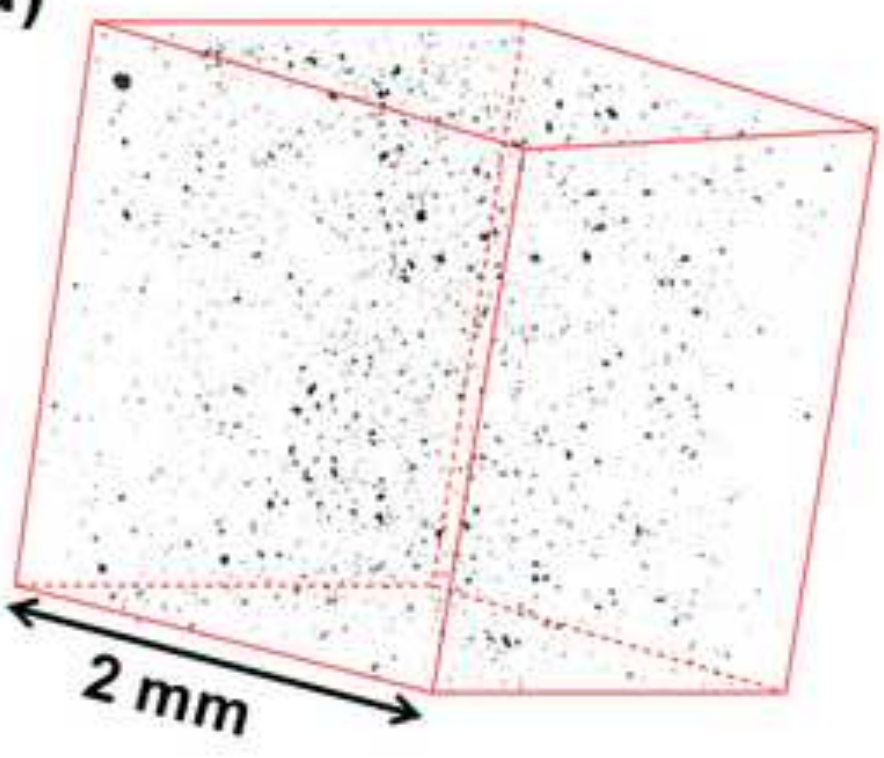




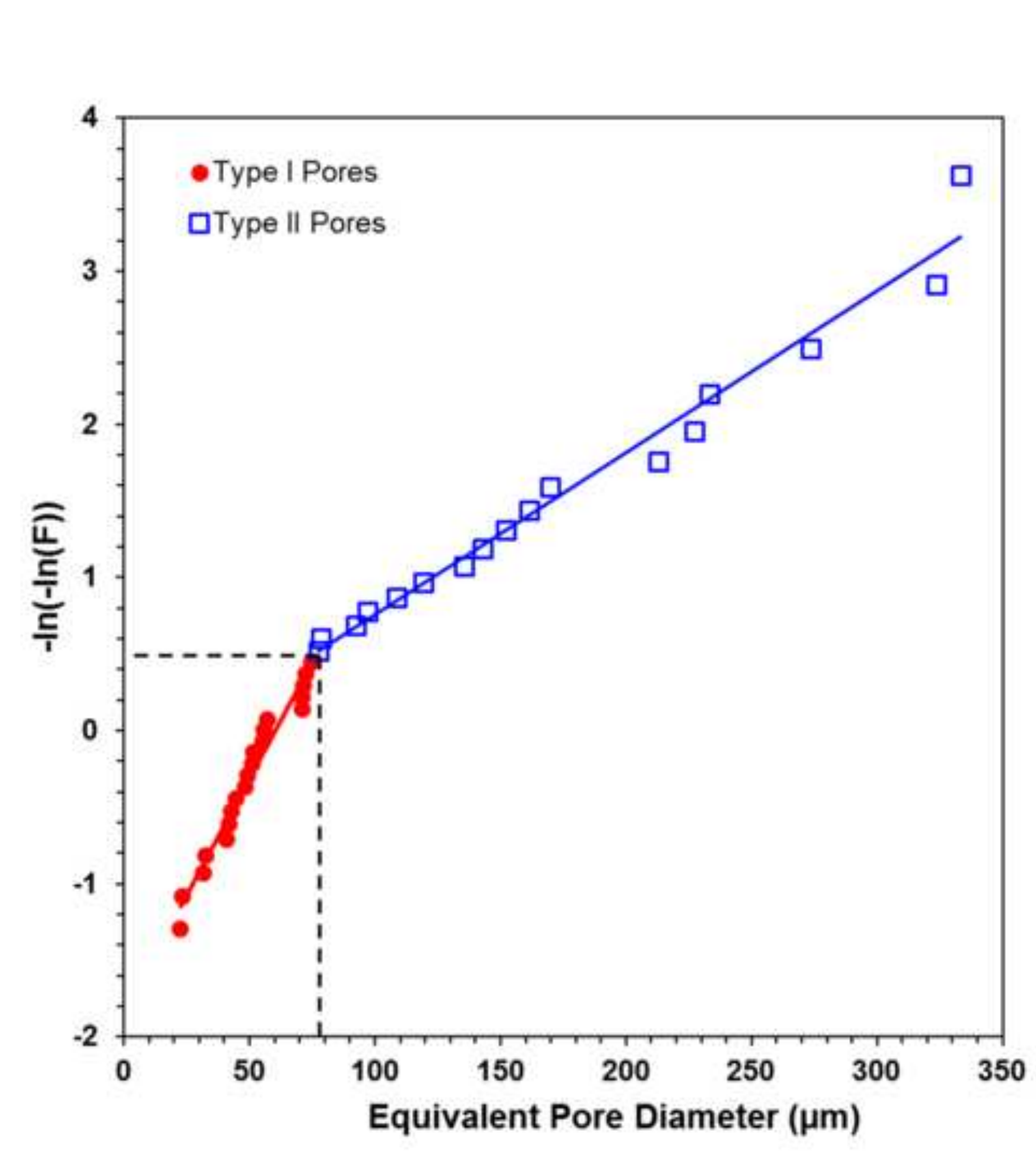

Fig. 3

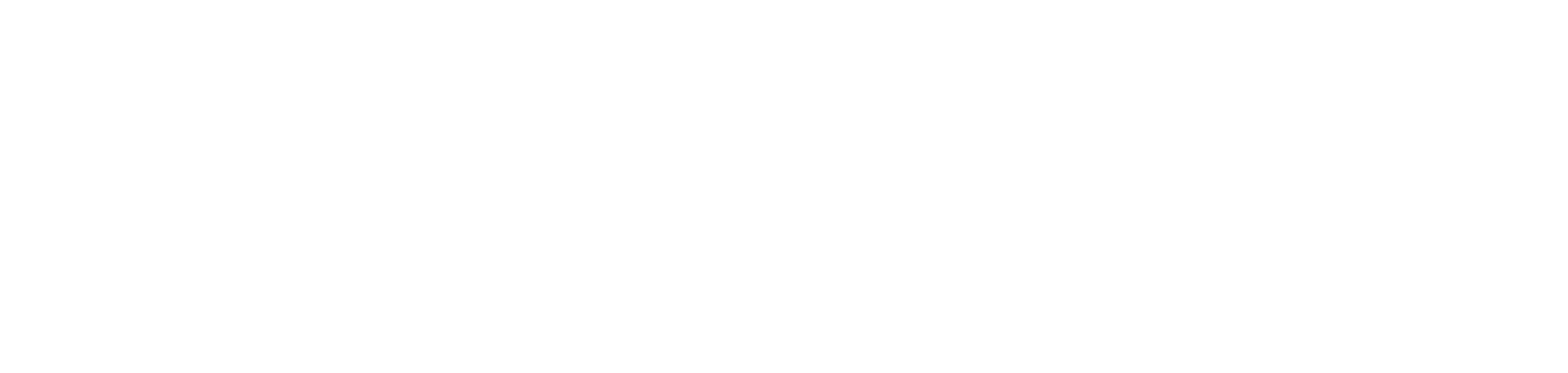

.

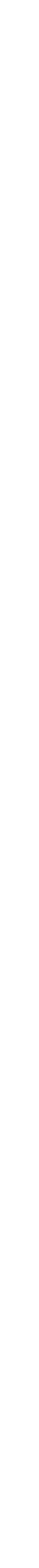

(1)
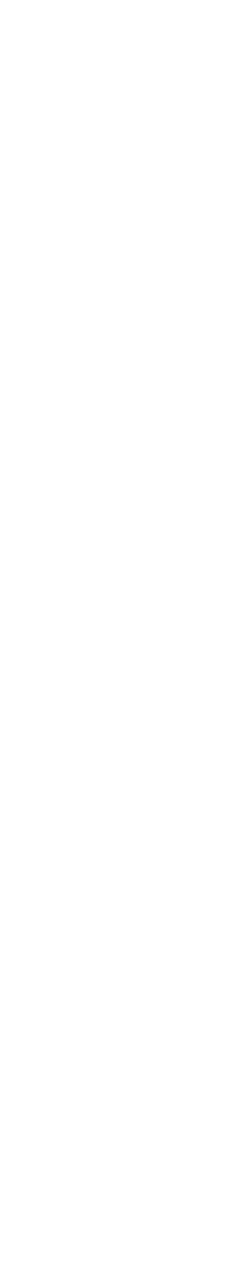


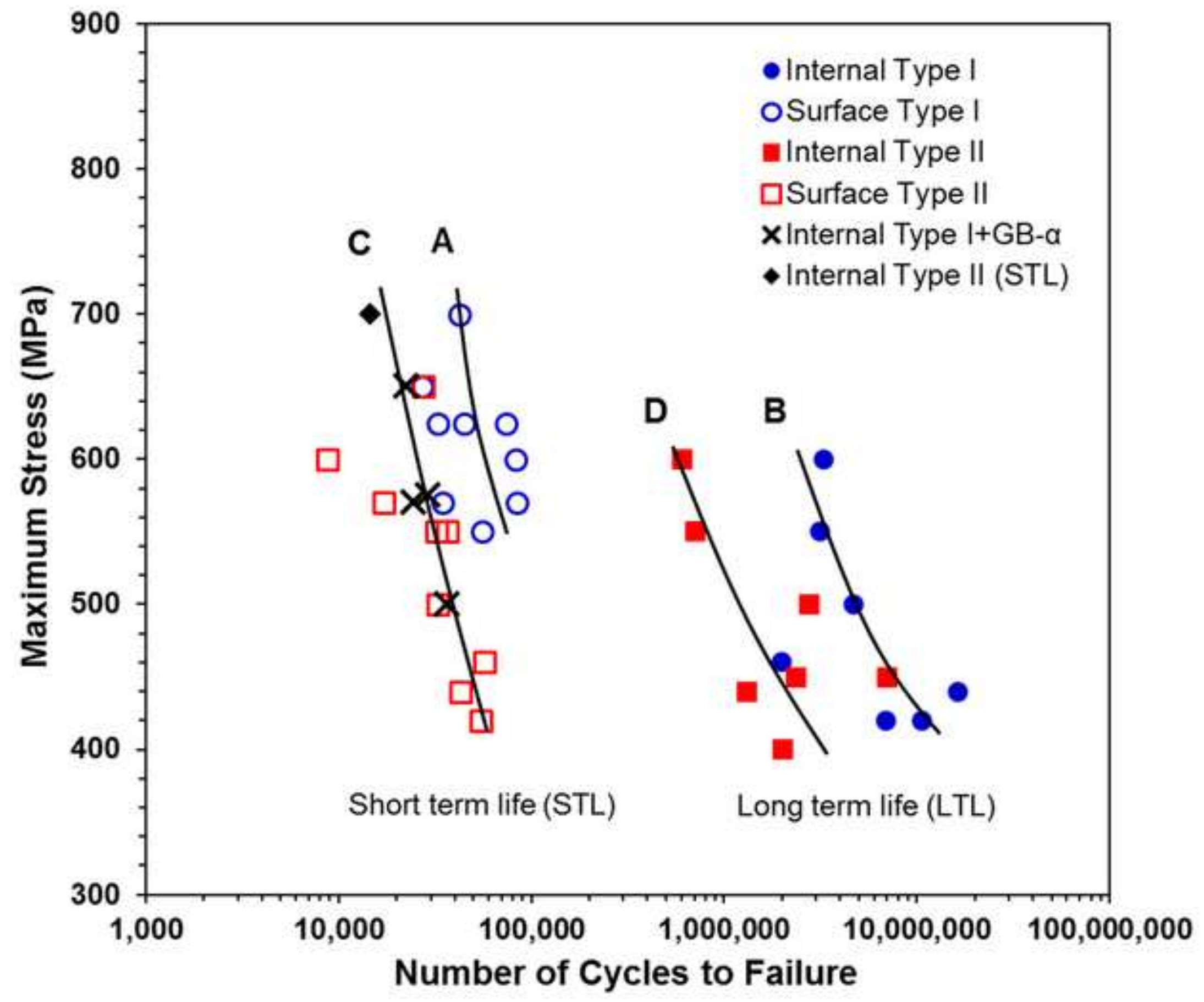




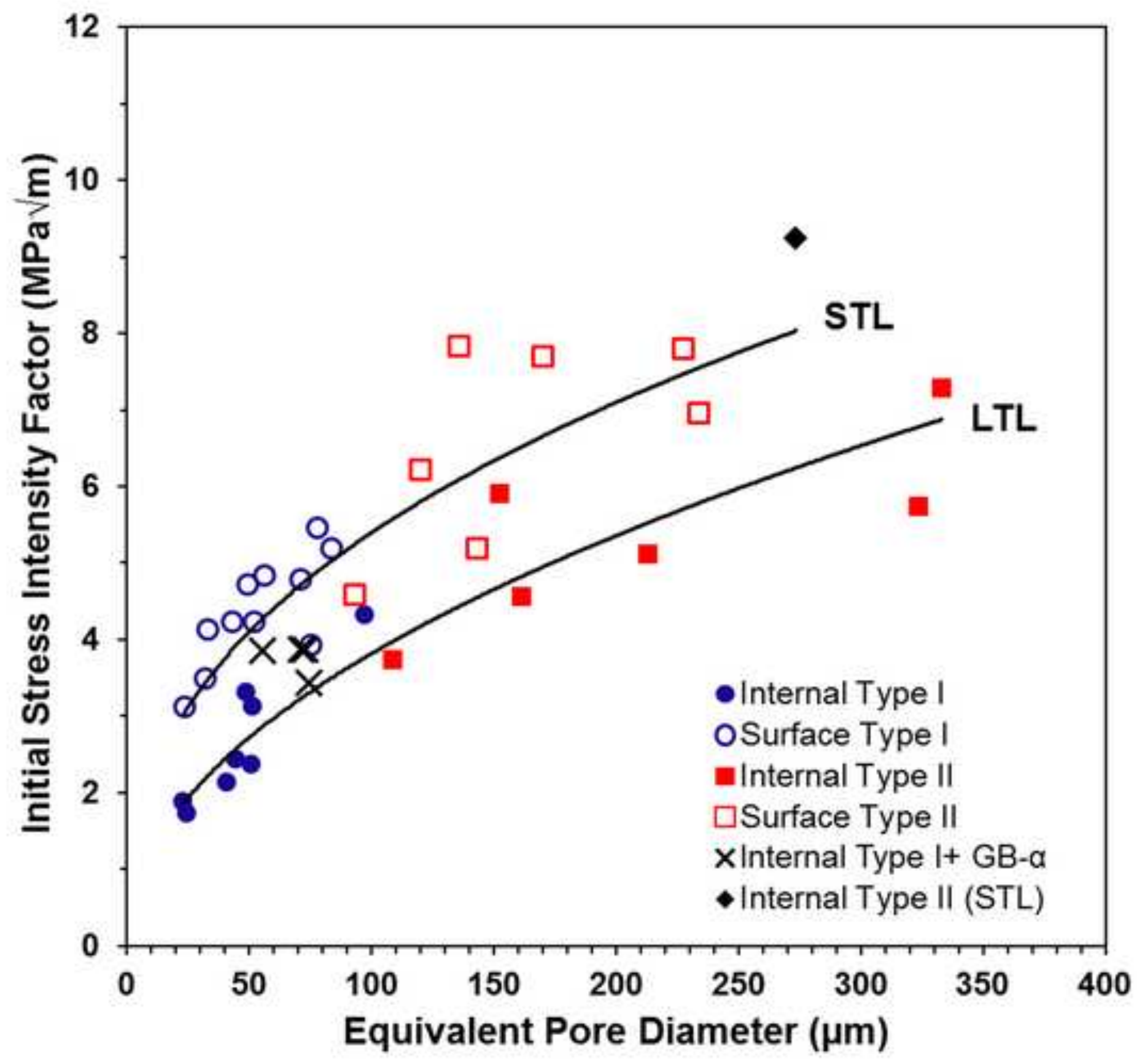




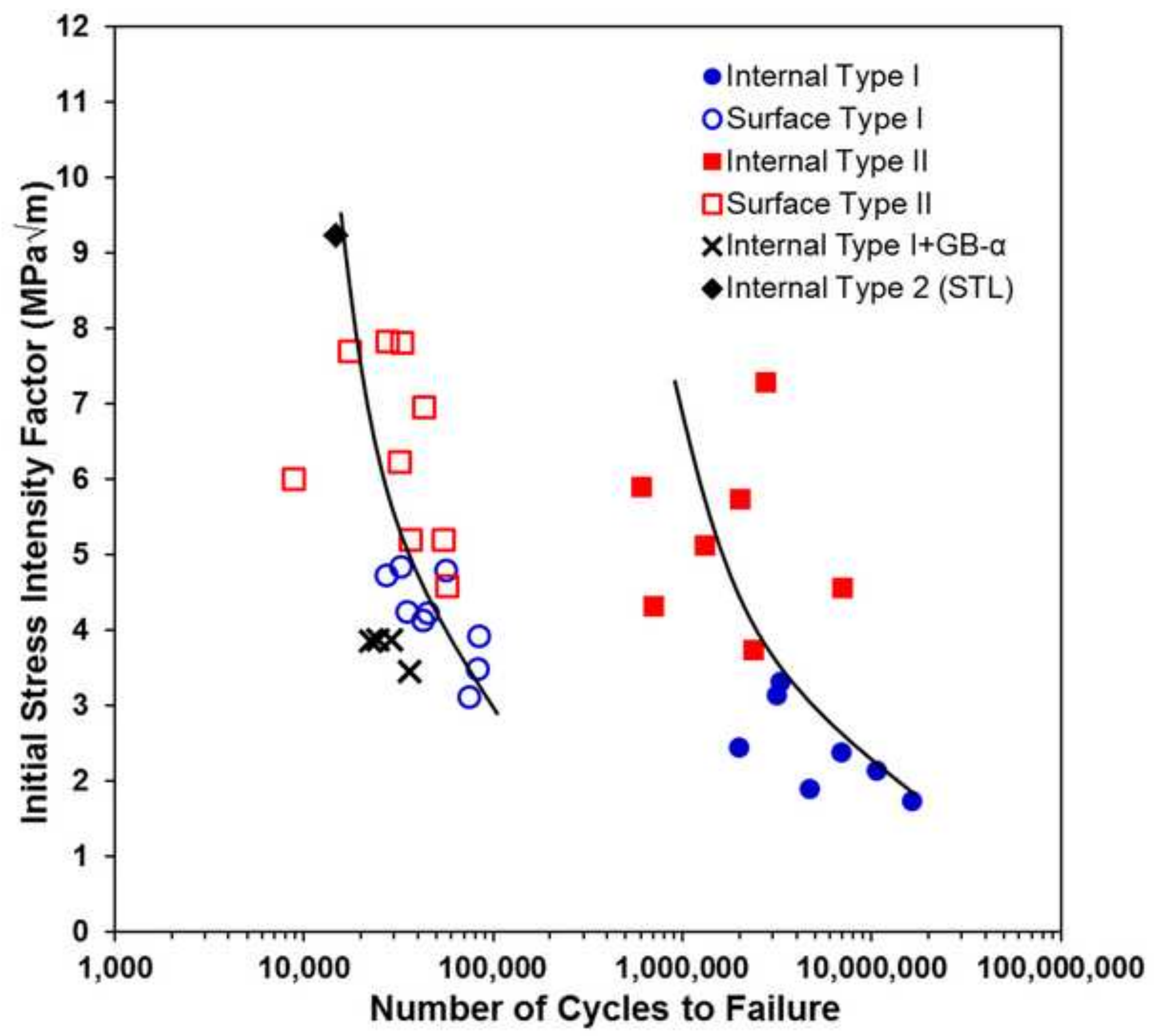

